\title{
Investigation of Possibility of Using Silicon Carbide Powder for Arc Welding and Build- Up Welding with Coated Electrodes
}

\author{
D. I. Yakubovich \\ State Institution of Higher Professional Education \\ "Belarusian-Russian University" \\ Mogilev, Republic of Belarus \\ E-mail: D.I.Yakubovich@mail.ru.
}

\author{
V.P. Grusha \\ State Scientific Institution "Institute of Metal Technology of \\ the National Academy of Sciences of Belarus" \\ Mogilev, Republic of Belarus \\ E-mail: gruv77@rambler.ru.
}

\begin{abstract}
This paper presents the findings of an investigation into the influence of silicon carbide on weld metal hardness in arc welding and build-up welding with coated electrodes. It is shown that the hardness of the weld bead increases with increasing silicon content. Decreasing the content of solid solution and increasing the content of mechanical mixture has a positive effect on hardness together with structural refinement of grains.
\end{abstract}

Keywords - manual arc build-up welding; hardness, silicon carbide.

\section{INTRODUCTION}

Build-up welding with coated electrodes is used for repairing and reconditioning fast wearing parts of gearboxes and other devices used in mechanical engineering which are subject to severe wear. The electrode coating composition has a significant effect on the process of alloying the metals both of weld beads and weld metal. When welding with coated electrodes, the presence of silicon is necessary as it influences the oxidation potential and improves mechanical properties.

Silicon contained in steel completely dissolves in ferrite and is present in $\alpha$-iron in the form of solid solution. The parameter values of its crystal lattice are smaller than those of iron. Consequently, in the process of crystallization the lattice parameters of $\alpha$-iron decrease, which results in ferrite hardening and its lower plasticity. The amount of silicon is of great importance for characteristics of the weld bead and the welded joint as a whole. It has a greater affinity for oxygen than it has for iron; as a result, silicon oxides $\mathrm{SiO} 2$ are formed. To increase crack resistance and impact strength, its content should not exceed $0.3-0.6 \%[1,2]$. Its higher content will negatively affect these properties, especially when it exceeds $1 \%[3,4]$.

The main alloying additives in the coating of the electrodes used for build-up welding are carbide-forming elements [511]. In the weld bead, these materials form phases with high hardness, and in combination with soft matrix, they provide high wear resistance. Such alloying particles in the electrode coating can reach a maximum size of several tenths of a millimeter. This approach to the production of build-up welding electrodes is a well-known process; the structures and the properties of the weld metal obtained by using these electrodes are well-studied and described in the literature $[7,12,13]$.
When choosing alloying elements for manufacturing buildup electrodes, cost and availability play an important role. In this regard, the use of silicon carbide powder (which, in fact, is a waste product) instead of expensive ferrosilicon is an important task.

This paper focuses on an investigation into the possibility of using silicon carbide in the coating of electrodes for manual arc welding and build-up welding.

The subject of this investigation is an examination of the influence of silicon carbide on the mechanical properties of build-up weld beads.

The object of this investigation is to study coated electrodes for manual arc welding UONNI 13/55 with a diameter of $3 \mathrm{~mm}$. The coating material of these electrodes contains ferrosilicon (FS-45) in the amount of $5-7 \%$ of the total composition.

For this study, it was suggested to add ferrosilicon FS-45 and silicon carbide to the standard coating of the UONNI 13/55 electrode.

\section{MATERIALS, EQUIPMENT AND METHODS OF RESEARCH}

For the experimental part of the study, the electrodes were made on the basis of the standard UONNI 13/55 electrode coating (GOST 9466-75). Two additional components were used in the coating of these electrodes. The first component is silicon carbide powder SiC. The second one is ferrosilicon FS45 as it is present in the coating composition of the abovementioned electrodes in the amount of 5-7\%.

To determine the effect of silicon carbide on the properties of the weld bead, four batches of electrodes were manufactured. In the manufacture of the first and second batches of electrodes, ferrosilicon in the amount of $5 \%$ and $20 \%$ by mass was added to the standard dry powder. In the manufacture of the third and fourth batches, silicon carbide in the amount of $5 \%$ and $20 \%$ was used.

Before the powders were added to the electrode powdered coating, they were mixed in a drum tumbler mixer for 2 hours. The particle size of the powders did not change after mixing.

When manufacturing a pilot batch of electrodes, it is not advisable to use mass production equipment and technologies. Therefore, for manufacturing coated electrodes by extruding, a 
laboratory technology was developed and special equipment was designed and manufactured. The applied equipment ensured fastening and alignment of the metal rod as well as uniform distribution of the required amount of the coating paste along the length of the electrode. The electrode coating of the required diameter without eccentricity was formed.

The manufactured electrodes were subject to natural drying at $18-25{ }^{\circ} \mathrm{C}$ for 24 hours and to drying in an oven at $70-80{ }^{\circ} \mathrm{C}$ for 1 hour followed by baking at $300-350{ }^{\circ} \mathrm{C}$ for 1.5 hours.

The influence of silicon carbide on mechanical properties of the weld metal was determined on samples made by manual arc welding.

Welding of samples for metallographic studies was carried out on plates from Steel 10 with a size of $150 \times 150 \mathrm{~mm}$ and 10 $\mathrm{mm}$ thick under the following conditions: welding current $I w$ $=110-120 \mathrm{~A}$, welding speed $\mathrm{Vw}=7-8 \mathrm{~m} / \mathrm{h}$, the electrode diameter $d=3 \mathrm{~mm}$. Minarc-220 power supply was used as a power source. The beveled angle and the gap between the plates corresponded to the welded joint of C17 type in accordance with the State Standard (GOST) 5264-80. Welding was performed in two passes. The dimensions of the weld beads obtained corresponded to the State Standard requirements (GOST) 5264-80.

The hardness of the weld metal was determined by eightpass build-up welding on Steel St3sp plates with the size of $120 \times 80 \times 20 \mathrm{~mm}$ and build-up welding area of at least $80 \times 40$ $\mathrm{mm}$. with complete cooling of each layer. The hardness was determined by the Brinell hardness test method with a TB 5004 hardness gauge with a diameter of a metal ball of $5 \mathrm{~mm}$ and a load force of $7.355 \mathrm{~N}$.

The microstructure was studied after the samples were etched in a solution with 5\% nitric acid and 95\% alcohol. The microscopes Labomet1 and CarlZeiss were used for metallographic analysis.

The evaluation of welding properties of electrodes was performed on T-pieces in accordance with the State Standard (GOST) 9466-75. The tests were carried out at $18{ }^{\circ} \mathrm{C}$ and air humidity of $72 \%$.

\section{RESEARCH RESULTS AND DISCUSSION}

The difference in the thickness of the coating in diametrically opposite sections of the manufactured electrodes did not exceed $0.09 \mathrm{~mm}$.

When welding with electrodes of batches 1 - 3, blister, porosity or overlap did not occur. (Fig. 1, pos. 1 - 3). There were no surface cracks and local micro cracks. The welding arc was easily excited and burned steadily. The coating melted uniformly and no fingernail was formed. No cracks and pores in the metal of the weld bead were found. The stable welding bead formation was observed.

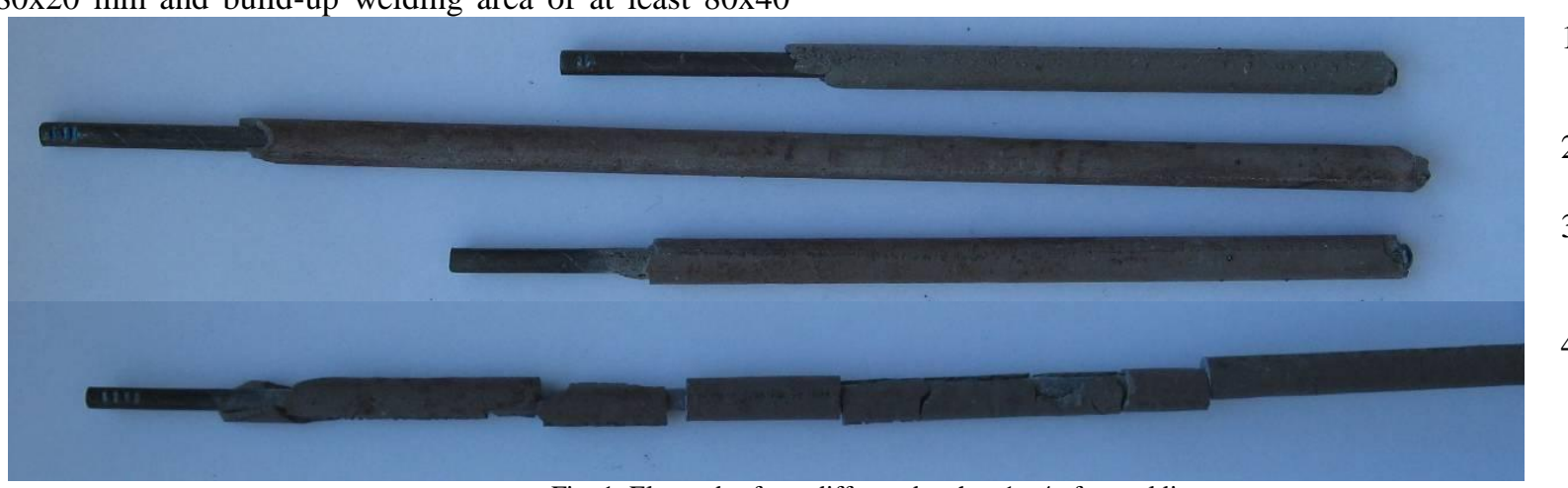

Fig. 1. Electrodes from different batches 1 - 4 after welding.

In the process of welding by using the electrodes of the fourth batch, the arc was excited easily, but it did not burn well, and the weld bead was difficult to form. In the metal of the weld bead, some slag inclusions and porosity were observed. When the electrode burned by $30-50 \%$, some cracking of the remaining part of the coating and its partial separation from the electrode rod occurred (Fig. 2, pos. 4). Reducing the welding current by $20 \mathrm{~A}$ did not lead to arc burning process stability and had no effect on preserving the integrity of the coating.

The appearance of cracks is caused by a change in the thermophysical properties and a decrease in the plasticity of the electrode coating with large SiC content.

The next stage of the study was to determine the hardness values for the weld bead and the weld metal. The values obtained are shown in Table 1.
TABLE I. HARDNESS OF WELD BEADS AND WELD METAL

\begin{tabular}{|c|c|c|}
\hline \multirow{2}{*}{$\begin{array}{c}\text { Electrode } \\
\text { batch number }\end{array}$} & \multicolumn{2}{|c|}{ Hardness, HB } \\
\cline { 2 - 3 } & weld bead & weld metal \\
\hline 1 & 196 & 229 \\
\hline 2 & 206 & 245 \\
\hline 3 & 217 & 269 \\
\hline 4 & 285 & - \\
\hline
\end{tabular}

Because of the coating cracking and impossibility of performing a high-quality eight-pass build-up welding by using the electrodes of the fourth batch, the hardness testing in the weld metal was not carried out.

The increase in hardness of the build-up weld bead occurs with an increase in the silicon content. After eight-pass buildup welding by the electrodes of batches 1 and 3, the hardness 


\section{$\triangle$ ATLANTIS

of the deposited layer averaged $229 \mathrm{HB}$ and $269 \mathrm{HB}$, respectively. The increase was $17 \%$, which is quite a logical result, since silicon carbide is a strengthening phase and forms solid structures in the process of crystallization of the weld bead.

The phase composition and structure of the matrix, where carbide inclusions are located, have a significant effect on the properties of the build-up weld metal. As for the overall hardness of the metal, the forming matrix must simultaneously hold the strengthening phase and have a high hardness response itself. Taking into account the phases formed in steels, the solid solution (ferrite) to a lesser degree and the

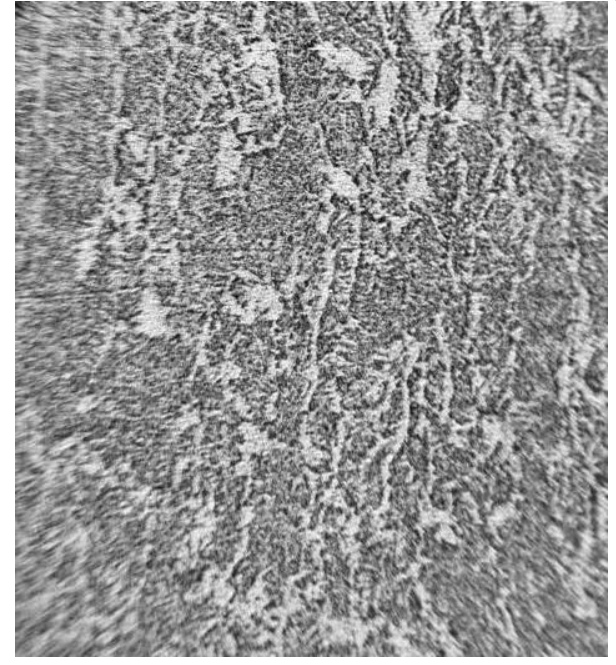

a mechanical mixture (perlite) or high-alloy austenite to a greater extent correspond to such properties [5]. The increase in the efficiency of carbides is associated with the appearance of coherent bond between the crystal lattices of carbides and the matrix.

The metallographic studies of welded beads showed that by adding $5 \%$ silicon carbide instead of $5 \%$ ferrosilicon resulted in a $2-4$ - fold structure refinement and a decrease in the amount of ferrite phase (Fig. 3).

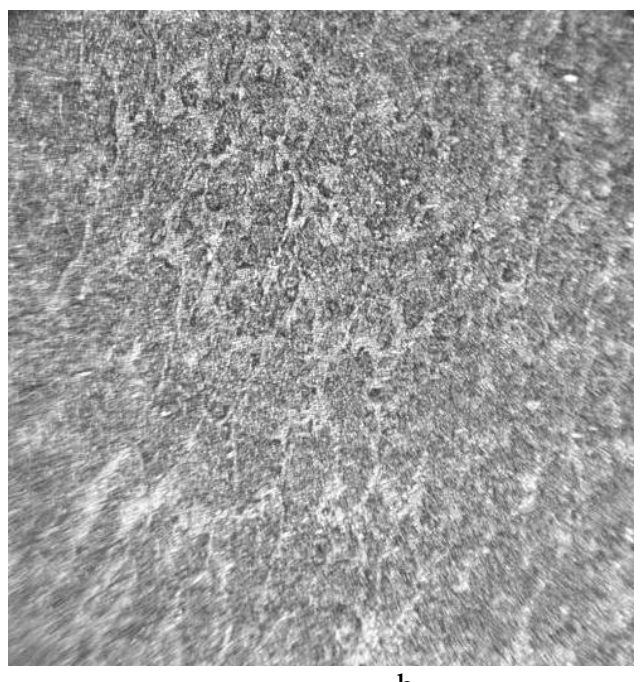

$\mathrm{b}$

Fig. 3. Microstructure of weld beads made with electrodes with addition of 5\% ferrosilicon (a) and 5\% silicon carbide (b).

Therefore, it can be concluded that with a decrease in the ferrite content the hardness increases.

The addition of $20 \%$ silicon carbide instead of $20 \%$ ferrosilicon to the coating of electrodes led to greater grain refinement of the structure. All grains had the form of a mechanical mixture of ferrite and carbide (Fig. 4).

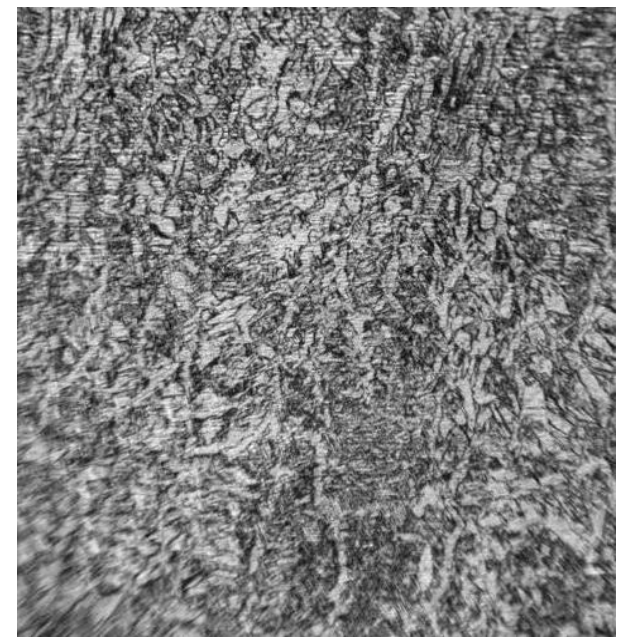

$\mathrm{a}$
With further change in structure and a greater amount of the mechanical mixture, the hardness of the build-up weld metal is found to increase.

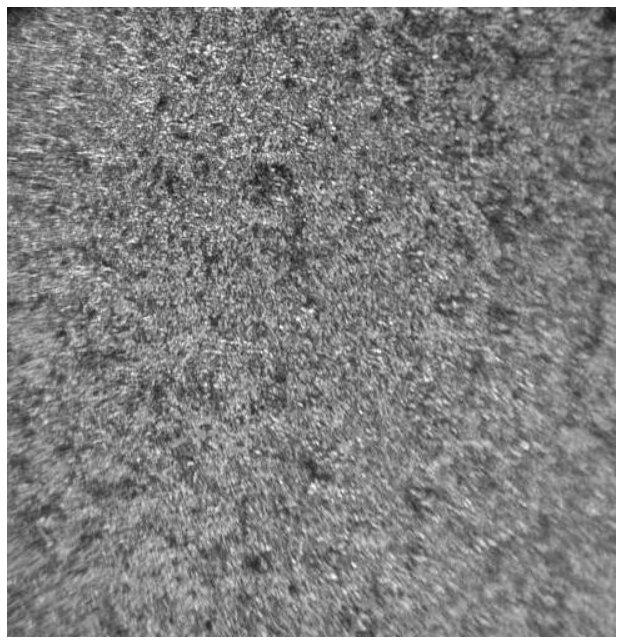

b

Fig. 4. Microstructure of weld beads made with electrodes with addition of $20 \%$ ferrosilicon (a) and $20 \%$ silicon carbide (b). 
The analysis of structures at 500x magnification allowed us to establish the reasons for the increase in hardness (Fig. 5). When examining the beads made with electrodes of the first and fourth batches, a significant increase in the number of
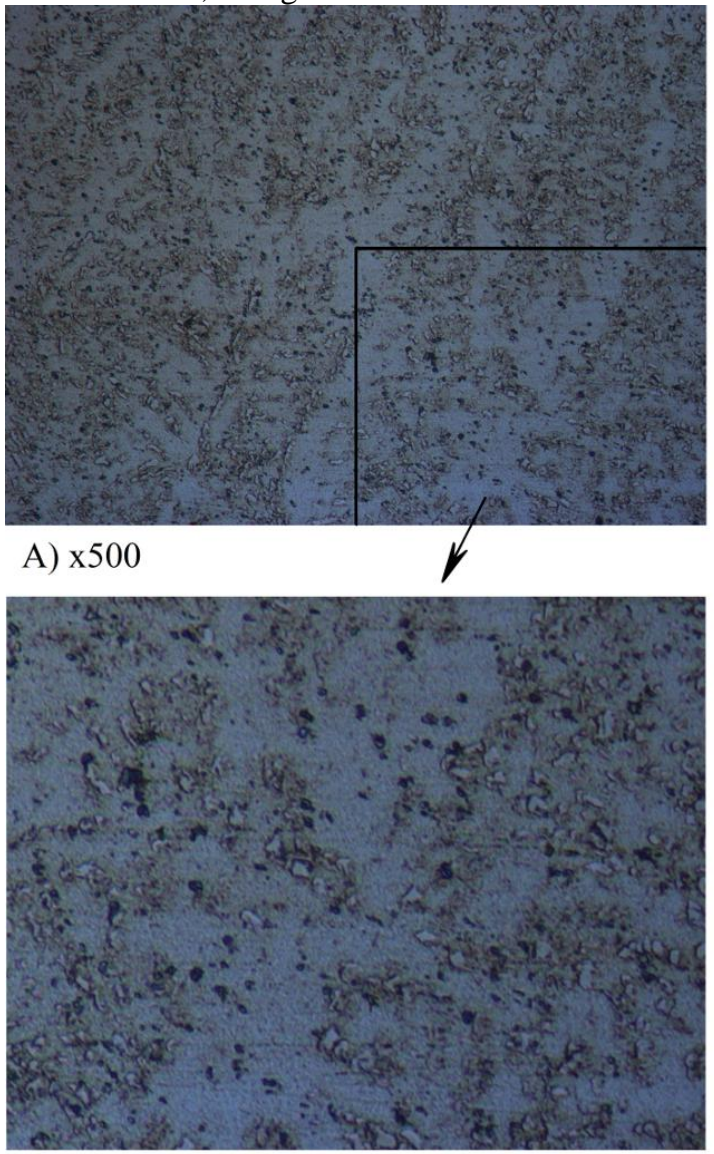

etch-resistant particles was observed; these particle have a white color and sizes of up to $10 \mu \mathrm{m}$.
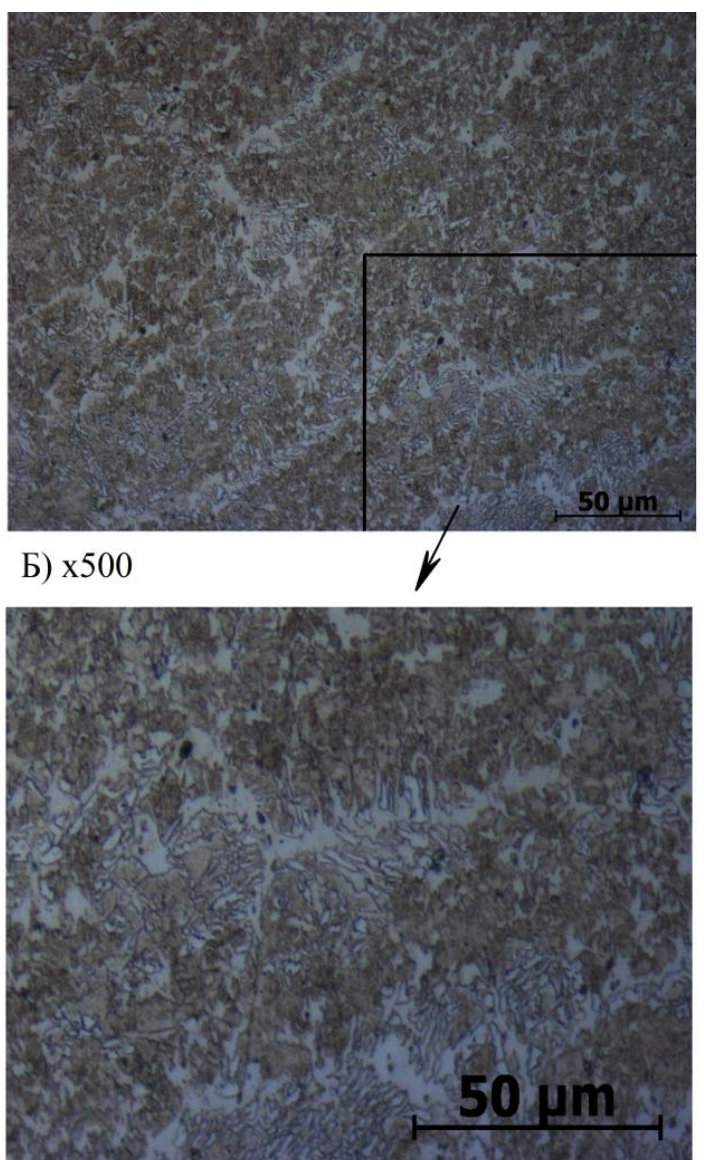

Fig. 5. Microstructure of weld beads made with electrodes with addition of $20 \%$ ferrosilicon (a) and $20 \%$ silicon carbide (b).

Thus, comparing the results obtained, it can be concluded that the use of $\mathrm{SiC}$ instead of $\mathrm{FeSi}$ or in addition to it as alloying and modifying additives is quite possible. Future research should be devoted to further study and implementation of the results obtained will be development of a new chemical composition of the build-up electrodes coating allowing us to obtain new properties of the weld metal..

\section{CONCLUSIONS}

It has been found possible to use silicon carbide powder in the coating of electrodes for manual arc welding as a modifier and a carbide-forming element.

It has been shown that the addition of $5 \% \mathrm{SiC}$ increased the hardness of the weld metal by $15-20 \%$ and resulted in grain refinement and a decrease in the amount of the ferrite phase.

Directions of further research in the field of development of new chemical compositions of electrodes coatings have been determined.

\section{References}

[1] I. K Pokhodnya, B. V.Yurlov, G. A. Shevchenko, I. R. Yavloshchin, "Effect of silicon on the structure and cold brittleness of the weld bead metal when welding low-alloy steels with high-performance electrodes with base coatings," Avtomaticheskaya svarka Publ., Vol. 2, pp. 1-6, 1987.

[2] L. I. Sorokin, A. A. Erokhin, "Effect of carbon, silicon and magnesium on the properties of weld metal in the welding of hightemperature alloys," Svarochnoe proizvodstvo Publ., Vol. 9, pp. 1213, 1972.

[3] A. E. Asnis, G. A. Ivashchenko, "Effect of silicon on the properties of welded joints of low-alloy steels," Avtomaticheskaya svarka Publ., Vol. 12, pp. 35-42, 1987.

[4] V. A. Struk, Material Science. Textbook. Minsk, IVTs Minfina Publ., 2008.

[5] A. I. Ryabtsev, I. K. Senchenkov, Theory and practice of build-up welding, Kiev, Ekotekhnologiya Publ., 2013.

[6] S.Ya. Shipitsin, Micro-reaction steel for railway wheels, Stal' Publ., Vol. 9. pp. 76-79, 2008.

[7] V. A. Kostin, G. M. Grigorenko, "The influence of the thermal welding cycle on the microstructure and properties of new structural steels with carbide and carbonitride hardening," Svarochnoe proizvodstvo Publ., Vol. 2, pp. 3-9.

[8] G. M. Grigorenko, "Investigations of the interfacial interaction of a ferrotype with silicon carbide in powder mixtures used for gas-thermal 
coating," Problemy sovremennoy elektrometallurgii Publ., Vol. 4, pp. 37-41, 2002.

[9] I. A. Ryabtsev, "Structure and wear resistance in abrasive wear of welded metal hardened by carbides of various types," Avtomaticheskaya svarka Publ., Vol. 5-6, pp. 84-88, 2015.

[10] E. F. Perepletchikov, I. A. Ryabtsev, V. G. Vasil'ev, Kh. Khayntse, "Structure and properties of iron-based high-carbon, high-vanadium alloys for build-up welding," Metallovedenie i termicheskaya obrabotka metallov Publ., Vol. 5, pp. 36-40, 2003.
[11] I. A. Ryabtsev, I. A. Kondrat'ev, V. G. Vasil'ev, L. K. Doroshenko, "Wear resistance of the weld metal of the Fe-C-Cr-Ti-Mo alloying system," Avtomaticheskaya svarka Publ., Vol. 4, pp. 48-51, 2002.

[12] E. A. Krivonosova, E. A. Sinkina, "Modeling of the carbide phase particles growth kinetics in a weld bead of high-alloy steels," Svarnoe proizvodstvo Publ., Vol. 6, pp. 3-6, 2013.

[13] V. M. Yazovskiy, E. A. Krivonosova, V. I. Shumyakov, I. Yu. Letyagin, "Optimization of the electrode coating composition with silicomanganese as a deoxidizer," Svarka v Sibiri Publ., Vol. 2, pp. 4648, 2005. 